\title{
Microsurgery: A 10-Year Experience with Loupe Magnification
}

\author{
Ferdinand Wanjala Nangole, MBChB, MMed ${ }^{1} \quad$ Stanley Ominde Khainga, MBChB, MMed ${ }^{1}$ \\ ${ }^{1}$ Department of Surgery, College of Health Sciences, University of \\ Nairobi, Nairobi, Kenya \\ J Reconstr Microsurg Open 2020;5:e90-e94. \\ Address for correspondence Ferdinand Wanjala Nangole, MBChB, \\ MMed, Department of Surgery, College of Health Sciences, University \\ of Nairobi, P.O. Box 2212-00202, Nairobi, Kenya \\ (e-mail: nangole2212@gmail.com).
}

\begin{abstract}
Keywords

- microsurgery

- free flaps

- reimplantation

- loupes

Microsurgical reconstructive procedures have now been well established in many centers globally. ${ }^{1}$ The practice is routinely utilized for both reconstructive and aesthetic procedures leading to better quality of life for the patients. In resourceconstrained settings, however, this brand of surgical practice is underutilized despite the fact that many patients could benefit from it. ${ }^{2}$ Among reasons for this is the unavailability of operating microscopes and lack of training in microsurgical techniques. ${ }^{3}$ Operating microscopes have been considered to have better outcomes than loupes magnification for microsurgical works. They are however beyond the reach of many reconstructive surgeons in many countries. Where they are available, they are shared by many disciplines such as ophthalmology, otolaryngology, and neurosurgery making it difficult to have them for routine or emergency reconstructive procedures. We share our experience with patients we operated on with loupe magnifications for the past 10 years on a wide range of reconstructive microsurgical procedures.
\end{abstract}

Background Microsurgical procedures are still rare in many countries especially in resource-constrained countries. Among reasons for this is the unavailability of operating microscopes that are costly. Operating loupes are considered inferior to the microscope and are most discouraged for many microsurgical procedures. We audit patients operated under loupes for the past 10 years and present our findings.

Patients and Methods This was a prospective audit of patients who underwent microsurgical reconstructive procedures in the plastic surgery unit at Kenyatta National Hospital between January 2009 and December 2019.

Results A total of 352 patients with 360 procedures were done over a 10-year period. The age range for the patients was 5 to 90 years. Free flaps accounted for $78 \%$ of the surgical procedures $(n=298)$ followed by nerve repairs $8.8 \%(n=32)$ and reimplantation surgeries $8.5 \%(n=30)$. The overall success rate for free flaps was $93.3 \%$ with reimplantations of $77 \%$. Conclusion Microsurgical reconstructive procedures as demonstrated in this study can safely be done with loupes. Loupes provide an alternative means of magnification that is cost effective and cheaper. In good hands, good surgical outcomes can be achieved that are comparable to the operating microscopes. received

May 20, 2020

accepted after revision

August 25, 2020
DOI https://doi.org/

10.1055/s-0040-1718517. ISSN 2377-0813.
The objective of this study was to audit microsurgical reconstructive procedures done under loupe magnification (×4.5-6) between January 2009 and December 2019 at the Division of Plastic Surgery, Kenyatta National Hospital, University of Nairobi, Kenya.

\section{Patients and Methods}

This study was approved by the local ethics and research committee. Patients who presented for microsurgical reconstructive procedure were prospectively followed up during the study period. Data captured included patients' demographics, pathology, anatomical location of the defects, and microsurgical procedures done. The procedures were broadly categorized into free flaps, reimplantations, lymph node transfer surgery, and nerve repairs. Patients were followed up for a minimum of 2 years to ascertain the outcome of the procedures. The surgical protocol for free flaps were topical

Copyright $\odot 2020$ by Thieme Medical Publishers, Inc., 333 Seventh Avenue, New York, NY 10001, USA. Tel: +1(212) 760-0888.
License terms

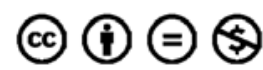




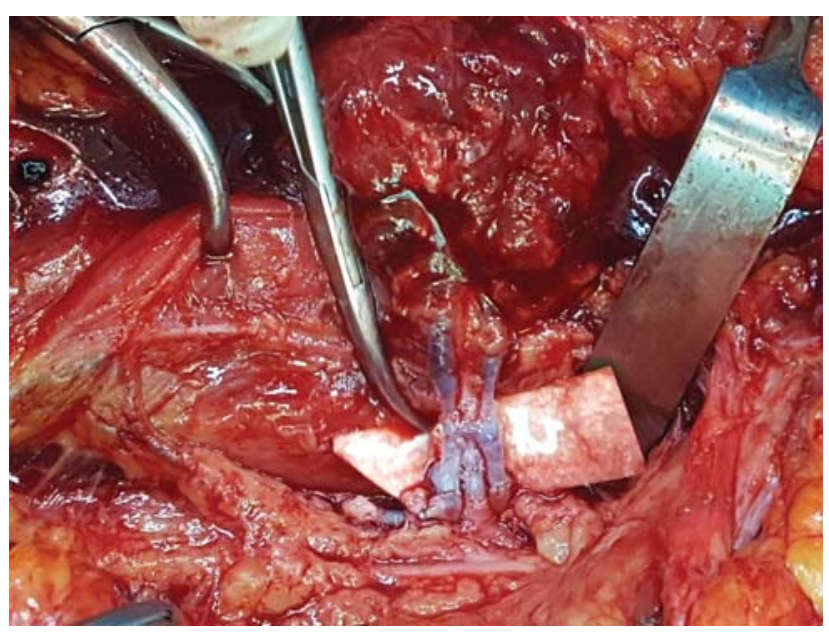

Fig. 1 Microvascular anastomosis of the free flaps. Note: two venous anastomoses.

irrigation of the vessels with heparin and lidocaine at the time of anastomosis, arterial anastomosis with nylon 9/0 sutures followed by venous anastomosis with the same suture. Two venous anastomoses except for cases where the flap had only one vein were routinely done (-Fig. 1). Postoperative monitoring of the flap was done every 4 hours for the first day, then every 6 hourly. The protocols for reimplantation were bone fixation first, followed by arterial anastomosis and then by venous anastomosis. This was then followed by repair of both flexor and extensor tendons and finally by repair of the nerves. Postoperatively, the reimplanted extremity was monitored every 2 hours for the first day, then every 4 hourly thereafter until the seventh postoperative day. The protocol for brachial plexus nerve repairs was primary nerve repairs if the injuries were open. Late nerve repairs were done on those that had failed conservative management. This was mainly by nerve transfers. Postoperatively, physical therapy was commenced after 2 weeks and followed up for at least 2 years. Patients with lymph node transfer surgery had limb measurements before surgery and after 1 month of surgery. Thereafter, serial measurements were done after every 3 months for at least 2 years.

\section{Results}

A total of 360 patients with 370 microsurgical procedures were managed with loupe magnification between January 2009 and December 2019. Three patients died in the perioperative period, while 5 patients were lost on follow-up leaving 352 patients with 360 procedures. The male:female ratio for the patients was 2:1. The age range was 5 to 90 years with a mean of 37 years and a median of 43.4 years. Head and neck reconstructions constituted $43.3 \%(n=156)$, lower limb defects $29.4 \% \quad(n=106)$, and reimplantations $8.5 \%$ $(n=30)$. - Table 1 summarizes the defects reconstructed. Free flaps constituted $75.8 \%$ of the microsurgical procedures done $(n=273)$. Radial forearm flap was the most common flap done $(n=76)$ followed by anterolateral thigh flap (ALT) $(n=74)$ and latissimus dorsi flap $(n=63)$. Overall flap success rate was $93 \%$. Reimplantation surgery constituted
Table 1 Defects reconstructed

\begin{tabular}{|l|l|l|}
\hline Defect & Frequency & Percentage \\
\hline Head and neck defects & 135 & 37.5 \\
\hline Lower limb defect & 95 & 26.4 \\
\hline Reimplantation surgeries & 30 & 8.5 \\
\hline Lymphedema & 29 & 8.0 \\
\hline Upper limb defects & 12 & 3.3 \\
\hline Nerve injuries & 32 & 8.8 \\
\hline Breast reconstruction & 10 & 2.7 \\
\hline Abdominal defects & 9 & 2.5 \\
\hline Thoracic defects & 8 & 2.2 \\
\hline Total & 360 & 100 \\
\hline
\end{tabular}

$8.3 \%$ of the procedures $(n=30)$ done with the hand being the most common replanted organ with $70 \%(n=21)$. The overall reimplantation success rate was $76.6 \%$. Nerve repairs including brachial plexus, upper limb, facial nerves, and lower limb nerves constituted $8.5 \%$ of the work done $(n=32)$. - Table 2 summarizes the reconstructive procedures done and the outcomes.

\section{Discussion}

Microsurgery has revolutionized management of many surgical conditions in various disciplines including plastic surgery, ophthalmology, urology, and neurosurgery. This practice still lags behind in many parts of the world due to the unavailability of the operating microscope and lack of training. ${ }^{2}$ Although operating microscopes may have advantages over loupes, this study demonstrated that it is not a prerequisite for microsurgical work. A good proportion and virtually any reconstructive microsurgical procedures can be safely done with loupe magnifications.

Free flaps accounted for more than $75 \%$ of microsurgical procedures done. The youngest patient operated on was a 3year-old boy with a facial defect that was reconstructed with ALT flap with the oldest patient with cancer of the larynx (-Fig. 2). Majority of the flaps done were either radial forearm, latissimus dorsi, or the ALT flap. ${ }^{4-7}$ These three are still the most common flaps done in many centers and safe for breast reconstruction. Radial forearm flap was commonly utilized for tongue reconstruction and smaller defects of the face. ALT and latissimus dorsi flaps were commonly used for larger defects of the legs and the face (-Figs. 2 and 3). Free flaps success rate in our study was 93.3\%. Other authors have also demonstrated good results with the use of loupes. Ashworth et al in a study comparing loupes and microscopy found both to be equally effective. ${ }^{8}$ Ehanire et al demonstrated a success rate of $95 \%$ on the use of loupes in the anastomosis of the radial forearm flap for oromaxillary defects. ${ }^{9}$ Another study by Passos et al on the use of loupes for head and neck reconstruction reported a success rate of more than $90 \%{ }^{10}$ Shenaq et al in a series of 
Table 2 Reconstructive procedures performed and outcomes

\begin{tabular}{|l|l|l|l|l|}
\hline $\begin{array}{l}\text { Microsurgical } \\
\text { procedure }\end{array}$ & Frequency & Successful & Failed & $\begin{array}{l}\text { Percentage } \\
\text { successful }\end{array}$ \\
\hline $\begin{array}{l}\text { Radial forearm } \\
\text { flap }\end{array}$ & 76 & 70 & 6 & 92 \\
\hline ALT flap & 74 & 71 & 3 & 96 \\
\hline $\begin{array}{l}\text { Latissimus dorsi } \\
\text { flap }\end{array}$ & 63 & 59 & 4 & 93.6 \\
\hline Free fibula flap & 39 & 35 & 4 & 89.7 \\
\hline Others & 21 & 19 & 2 & 90 \\
\hline $\begin{array}{l}\text { LN transplant } \\
\text { surgery }\end{array}$ & 29 & 20 & 9 & 69 \\
\hline $\begin{array}{l}\text { Brachial } \\
\text { plexus/upper } \\
\text { limb nerve }\end{array}$ & 28 & 17 & 11 & 60 \\
\hline Cross facial nerve & 1 & 1 & 1 & 100 \\
\hline $\begin{array}{l}\text { Lower limb nerve } \\
\text { repairs }\end{array}$ & 3 & 2 & 1 & 67 \\
\hline $\begin{array}{l}\text { Hand } \\
\text { reimplantation }\end{array}$ & 21 & 17 & 5 & 77 \\
\hline $\begin{array}{l}\text { Penile } \\
\text { reimplantation }\end{array}$ & 1 & 1 & 0 & 100 \\
\hline $\begin{array}{l}\text { Thumb } \\
\text { reimplantation }\end{array}$ & 2 & 1 & 1 & 50 \\
\hline $\begin{array}{l}\text { Finger } \\
\text { reimplantation }\end{array}$ & 4 & 3 & 1 & 75 \\
\hline $\begin{array}{l}\text { Foot } \\
\text { reimplantation }\end{array}$ & 1 & 325 & 38 & 100 \\
\hline $\begin{array}{l}\text { Ear } \\
\text { reimplantation }\end{array}$ & 1 & 1 & 0 \\
\hline Total & 160 & 1 & 67 \\
\hline
\end{tabular}

Abbreviations: ALT, anterolateral thigh; LN, lymph node.

more than 200 patients who underwent either free flaps or reimplantation reported a success rate of more than $97 \%$ with the use of loupes. ${ }^{11}$ Pannucci et al in an even larger series of more than 1,600 patients reported a success rate of more than $98 \%$ for patients who had free flap reconstructions of the breast with loupe magnification. ${ }^{12}$

The most challenging reconstructive work we encountered over the study duration was reimplantation of the cut extremities. Reimplantations constituted $8.5 \%$ of the microsurgical procedures done in the unit. Being emergency procedures, they were done in suboptimal environment both for the surgical team and the patients. The average ischemic time for our patients was 12 hours with about onethird of the patients taking more than 20 hours. Majority had extensive zone of injuries necessitating the use of both arterial and venous grafts with an average of eight anastomoses per reimplant ( - Fig. 4). Despite all this challenges, our overall reimplantation success rate was about $77 \%$ which compares favorably to centers that use microscopes. ${ }^{13,14}$ Shenaq et al reported a success rate of $76 \%$ with the use of loupes in reimplantations of the cut extremities. ${ }^{11}$ Mathieu et al reported a success rate of $50 \%$ in two cases that they performed. ${ }^{15}$ Our youngest patient was a 5 -year-old child with a right hand cut with a chuff cutter. The hand was successfully salvaged after reimplantation using loupes (-Fig. 5A-C).

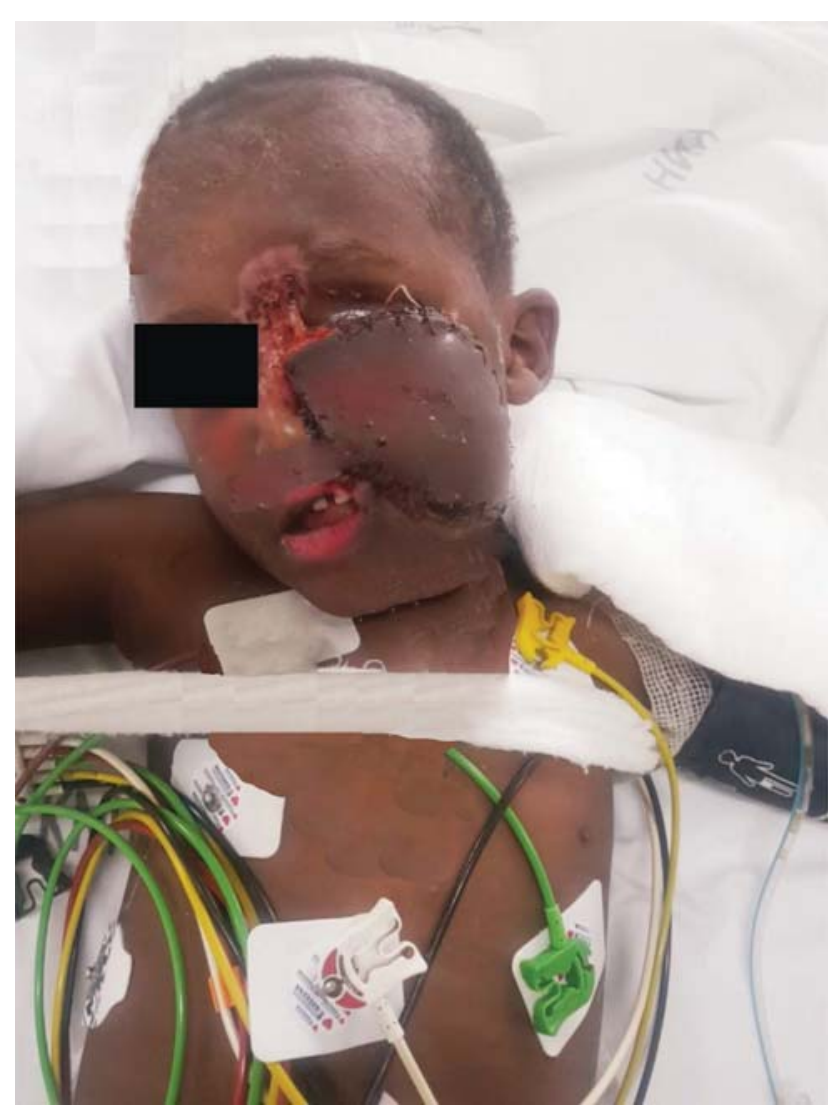

Fig. 2 Anterolateral thigh flap used to reconstruct facial defect of a 3year-old boy.

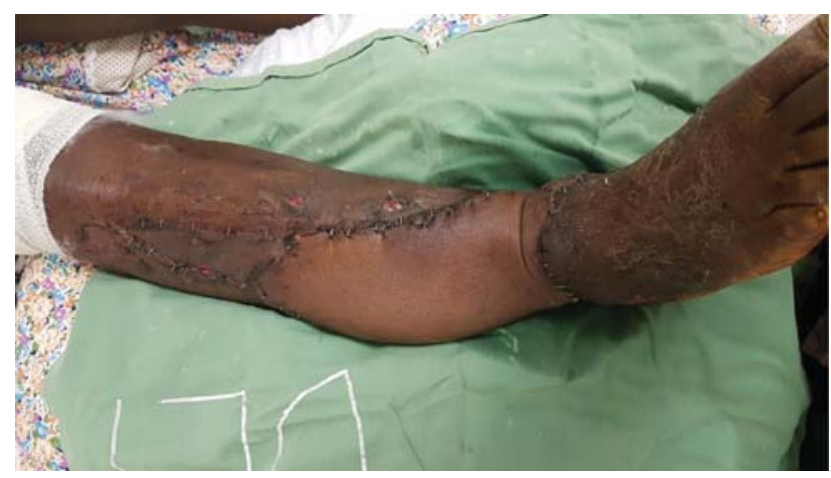

Fig. 3 Patient with a leg defect reconstructed with a free anterolateral thigh flap.

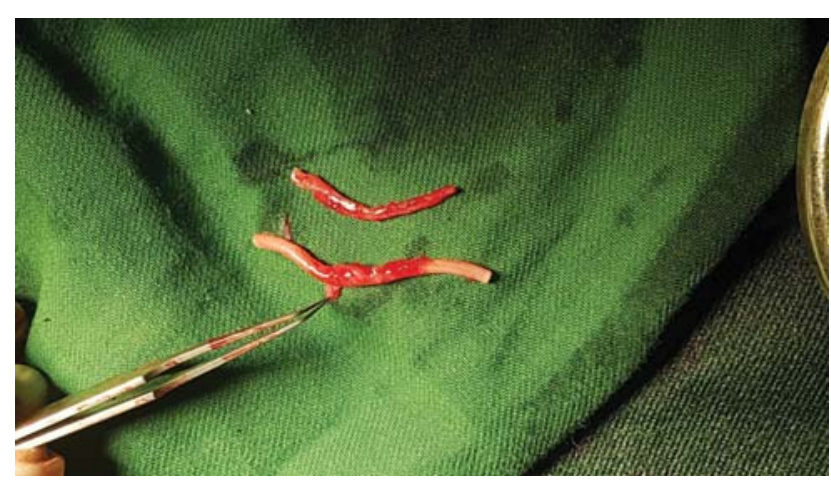

Fig. 4 Arterial and venous grafts harvested ready to be used for reimplantation of the hand. 

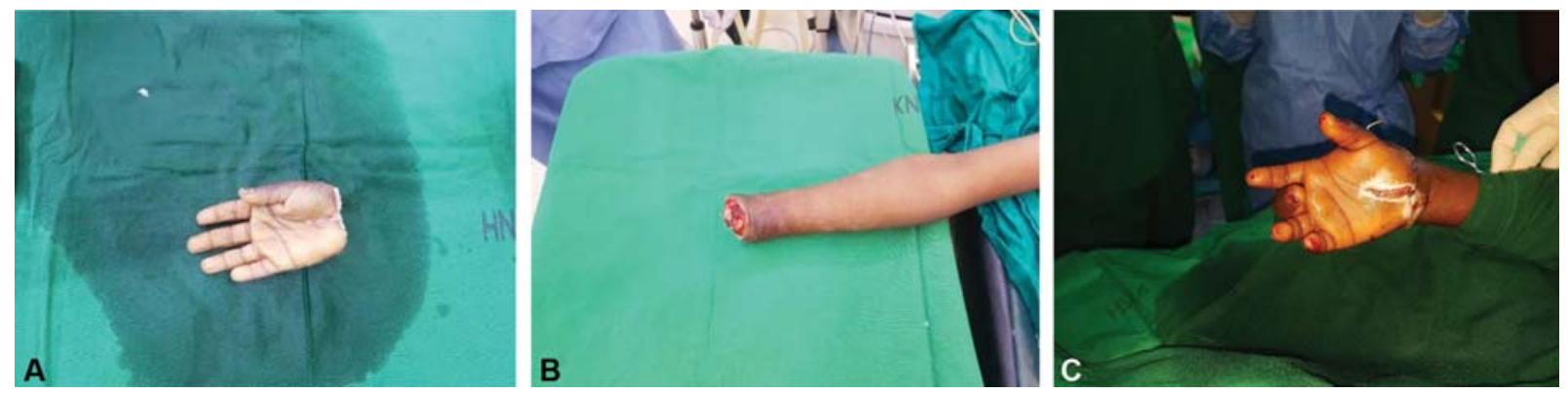

Fig. 5 (A) Cut hand in a 5-year-old child ready for reimplantation. (B) Cut forearm of the patient in (A), ready for reimplantation. (C) Cut hand in (A), successfully reimplanted at 1 week of follow-up.

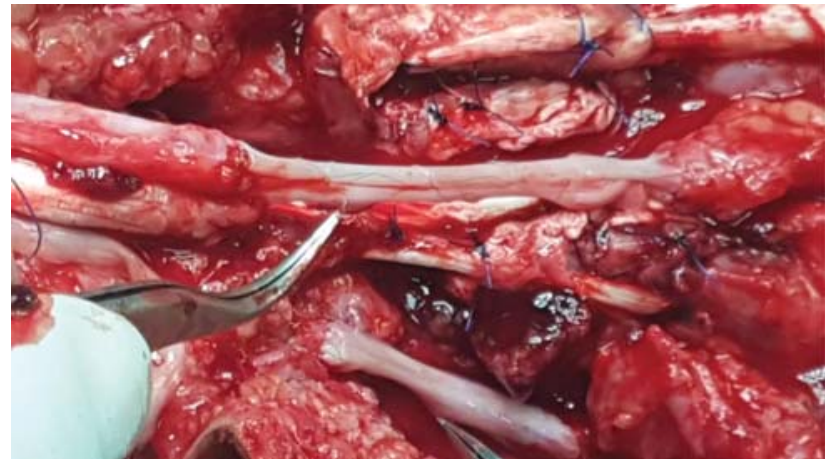

Fig. 6 Brachial plexus nerve injury repaired with nerve grafts.

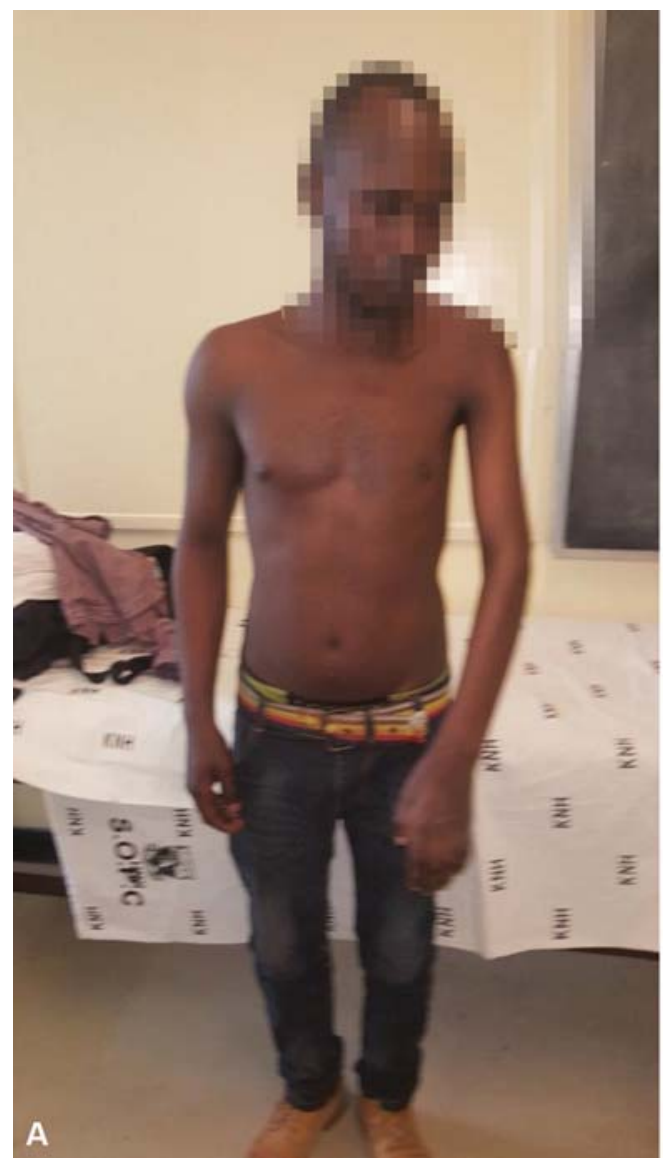

The most commonly done procedures for the nerves were either nerve grafts or nerve transfers. Sural nerve was the nerve graft of choice. All repairs done were epineural with nylon 9/0 (-Fig. 6). Outcome of brachial plexus surgery varied widely. Factors that might have influenced the outcomes included time of presentation, extent of injury whether partial or pan brachial plexus, type of injuries whether sharp or blunt trauma, and the patient's willingness or ability to come for postoperative rehabilitation. Overall, at least $60 \%$ of the patients had some sensory or motor recovery with some ability to abduct shoulder or flex the elbow joint ( - Fig. 7A, B). Lower limb nerve repairs also reported both sensory and motor recovery of varying degrees. ${ }^{16}$

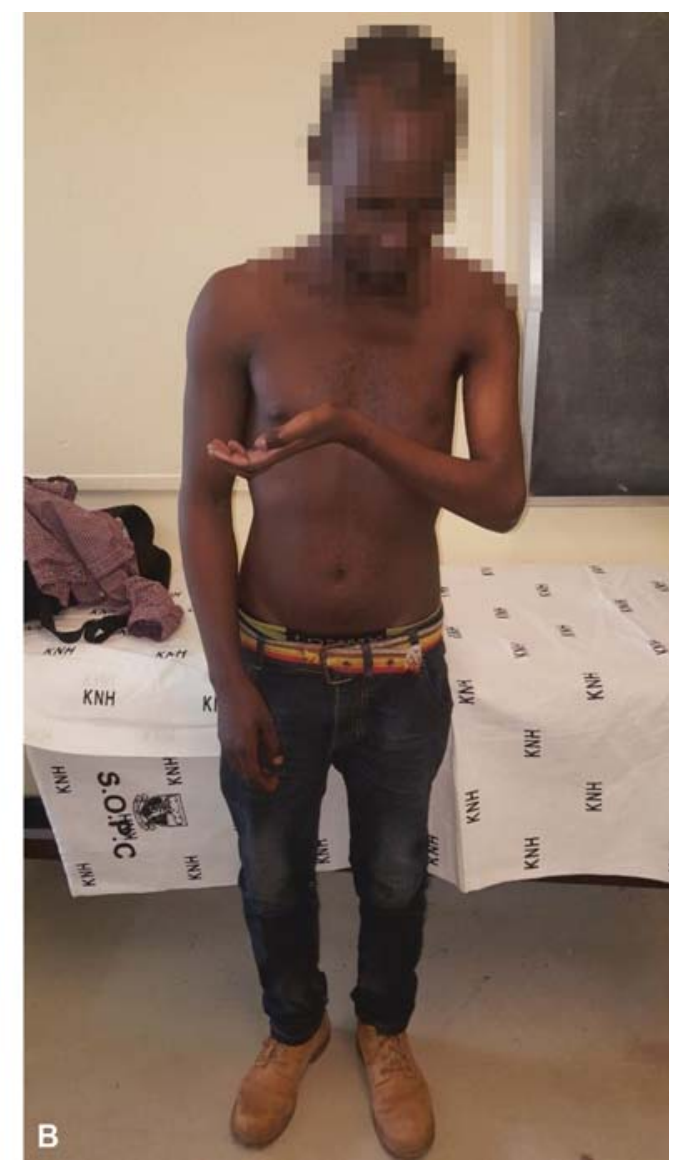

Fig. 7 (A) Patient with left arm brachial plexus nerve injury notes muscle wastage. (B) Patient in (A) after nerve transfers for repair of brachial nerve palsy. Note: ability to flex the elbow. 
Vascularized lymph node transfer surgery accounted for about $8 \%$ of the surgical procedures done. The nodes were harvested in the submental area and anastomosed in the most depended parts of the body. Clinical improvement was noted in $67 \%$ of the patients with reduction in the limb circumferences and improvement in symptomatology. ${ }^{17}$ Cheng et al reported an improvement of about $97 \%$ in all patients whom they managed with vascularized lymph node transfer surgery. ${ }^{18}$

\section{Conclusion}

The outcome of microsurgical reconstructive procedures as demonstrated in our study is not solely dependent on the type of magnifications. Good outcomes can be achieved irrespective of whether one uses loupes or operating microscopes. Though microscopes have advantages of better magnification, they are more expensive and more difficult to mount before operations. They are also delicate and more prone to damages than loupes. Loupes provide an alternative means of magnification that is cost effective and cheaper. In good hands, good surgical outcomes can be achieved that compare to the operating microscopes. In many resourceconstrained countries, loupes provide an alternative option in doing microsurgical reconstructive procedures.

Conflict of Interest

None declared.

\section{References}

1 Tang JB, Saint-Cyr M. Microsurgery half a century after establishment: global perspectives. Clin Plast Surg 2017;44(02):xiii-xiv

2 Nangole WF, Khainga S, Aswani J, Kahoro L, Vilembwa A. Free flaps in a resource constrained environment: a five-year experienceoutcomes and lessons learned. Plast Surg Int 2015;2015:194174

3 Banda CH, Georgios P, Narushima M, Ishiura R, Fujita M, Goran J. Challenges in global reconstructive microsurgery: the sub-Saharan African surgeons' perspective. JPRAS Open 2019;20:19-26

4 Lim YS, Kim JS, Kim NG, Lee KS, Choi JH, Park SW. Free flap reconstruction of head and neck defects after oncologic ablation: one surgeon's outcomes in 42 cases. Arch Plast Surg 2014;41(02): 148-152

5 Vincent A, Kohlert S, Lee TS, Inman J, Ducic Y. Free-flap reconstruction of the tongue. Semin Plast Surg 2019;33(01):38-45

6 Pu LLQ. A comprehensive approach to lower extremity free-tissue transfer. Plast Reconstr Surg Glob Open 2017;5(02):e1228

7 Kang MJ, Chung CH, Chang YJ, Kim KH. Reconstruction of the lower extremity using free flaps. Arch Plast Surg 2013;40(05): 575-583

8 Ashworth DR, Whear NM, Fan V. Radial free flaps using loupe magnification: audit of 97 cases of orofacial reconstruction. $\mathrm{Br} \mathrm{J}$ Oral Maxillofac Surg 2004;42(01):36-37

9 Ehanire T, Singhal D, Mast B, Leyngold M. Safety of microsurgery under loupes versus microscope: a head-to-head comparison of 2 surgeons with similar experiences. Ann Plast Surg 2018;80(6S, suppl 6):S340-S342

10 Passos GD, Price CE, Piennar CH. Loupe magnification for head and neck free flap reconstruction in a developing country. Eur J Plast Surg 2015;87(02):217-312

11 Shenaq SM, Klebuc MJ, Vargo D. Free-tissue transfer with the aid of loupe magnification: experience with 251 procedures. Plast Reconstr Surg 1995;95(02):261-269

12 Pannucci CJ, Basta MN, Kovach SJ, Kanchwala SK, Wu LC, Serletti JM. Loupes-only microsurgery is a safe alternative to the operating microscope: an analysis of 1,649 consecutive free flap breast reconstructions. J Reconstr Microsurg 2015;31(09): 636-642

13 Sebastin SJ, Chung KC. A systematic review of the outcomes of replantation of distal digital amputation. J Hand Microsurg 2017; 9(02):92-94

14 Tatebe M, Urata S, Tanaka K, Kurahashi T, Takeda S, Hir H. Survival rate of limb replantation in different age groups. J Orthop Surg (Hong Kong) 2018;(10):12-29

15 Mathieu L, Levadoux M, Landevoisin ES, McBride TJM, Rigal S. Digital replantation in forward surgical units: a cases study. SICOT J 2018;4:9. doi:10.1051/sicotj/2018004

16 Ferdinand NW, Raduma OS. Post thermal sciatic nerve injury successfully repaired with a sural nerve graft: case report. J Surg 2019;7(05):119-122

17 Wamalwa AO, Nangole FW, Khainga SO. Lymph node transplant in Kenya: a case series of 20 patients - plastic surgery. S Afr J Surg 2019;57(01):54-59

18 Cheng M-H, Loh CYY, Lin C-Y. Outcomes of vascularized lymph node transfer and lymphovenous anastomosis for treatment of primary lymphedema. Plast Reconstr Surg Glob Open 2018;6(12): e2056 